\title{
Chapter 4 \\ Application of Mass Spectrometry for Analysis of Cesium and Strontium in Environmental Samples Obtained in Fukushima Prefecture
}

\author{
Analysis of Cesium Isotope Compositions in \\ Environmental Samples by Thermal Ionization Mass \\ Spectrometry-2
}

\author{
Yuji Shibahara, Takumi Kubota, Satoshi Fukutani, Toshiyuki Fujii, \\ Koichi Takamiya, Tomoko Ohta, Tomoyuki Shibata, Masako Yoshikawa, \\ Mitsuyuki Konno, Satoshi Mizuno, and Hajimu Yamana
}

\begin{abstract}
For the assessment of Fukushima Daiichi Nuclear Power Plant accident, the applicability of the thermal ionization mass spectrometry (TIMS), which is a type of mass spectrometry, was studied. For the study of the recovery/analysis method of cesium and strontium, at first, the radioactive cesium and strontium were generated by the irradiation of natural uranium at KUR. After this study, the applicability of this method to the environmental samples obtained in Fukushima prefecture was verified.
\end{abstract}

Keywords Fukushima Dai-ichi Nuclear Power Plant accident • Strontium • Cesium • Chromatography • Mass spectrometry • Isotopic ratio

\footnotetext{
Y. Shibahara $(\varangle) \bullet$ T. Kubota $\bullet$ S. Fukutani • T. Fujii • K. Takamiya • H. Yamana

Kyoto University Research Reactor Institute, 2, Asashiro-Nishi, Kumatori-cho, Sennan,

Osaka 590-0494, Japan

e-mail: y-shibahara@rri.kyoto-u.ac.jp

T. Ohta

Hokkaido University, Kita 8, Nishi 5, Kita-ku, Sapporo, Hokkaido 060-8628, Japan

T. Shibata $\bullet$ M. Yoshikawa

Kyoto University Institute for Geothermal Sciences, Noguchi-baru, Beppu, Oita 874-0903, Japan

M. Konno • S. Mizuno

Nuclear Power Safety Division, Fukushima Prefectural Government, 8-2 Nakamachi, Fukushima, Fukushima 960-8043, Japan
} 


\subsection{Introduction}

On the accident of Fukushima Daiichi Nuclear Power Plant (FDNPP), fission products (FP) such as radioactive $\mathrm{Cs}$ and $\mathrm{Sr}$ were widely released. The amounts of FP generated in each reactor were calculated by using ORIGEN code [1]. Many studies of radioactive $\mathrm{Cs}$ and $\mathrm{Sr}$ were performed to estimate external and internal exposures and to analyze the source of radioactive nuclides. These studies were typically performed by $\gamma$-ray spectrometry of ${ }^{134} \mathrm{Cs}\left(\mathrm{T}_{1 / 2}=2.06 \mathrm{y}\right)$ and ${ }^{137} \mathrm{Cs}$ $\left(\mathrm{T}_{1 / 2}=30.2 \mathrm{y}\right)$ for the analysis of radioactive $\mathrm{Cs}$ and by $\beta$-spectrometry of ${ }^{90} \mathrm{Sr}$ $\left(\mathrm{T}_{1 / 2}=28.9 \mathrm{y}\right)$ for that of radioactive $\mathrm{Sr}$.

In addition to ${ }^{134} \mathrm{Cs}$ and ${ }^{137} \mathrm{Cs}$, radioactive ${ }^{135} \mathrm{Cs}\left(\mathrm{T}_{1 / 2}=2.3 \times 10^{6}\right)$ is also generated during the operation of reactors. Because of the difference in the generation process and the half-life of radioactive $\mathrm{Cs}$, the isotopic ratios of ${ }^{134} \mathrm{Cs} /{ }^{137} \mathrm{Cs}$ and ${ }^{135} \mathrm{Cs} /{ }^{137} \mathrm{Cs}$ have been used for analyzing the operations of nuclear facilities [2-6]. Naturally occurring Sr has four stable isotopes $\left({ }^{84} \mathrm{Sr},{ }^{86} \mathrm{Sr},{ }^{87} \mathrm{Sr}\right.$, and $\left.{ }^{88} \mathrm{Sr}\right)$, on the other hand, and the isotopic composition of Sr generated in reactors [1] are totally different from the natural abundance [7]. From the analysis data of the isotopic compositions, thus, the information on the origin of radioactive nuclide release would be obtained. The mass spectrometry provides the isotopic compositions of elements. Although mass spectrometry has been used for the analysis of radioactive nuclides and actinides, few studies have reported the analysis of radioactive Cs and $\mathrm{Sr}$.

The purpose of the present study is to analyze $\mathrm{Cs}$ and $\mathrm{Sr}$ isotopes in environmental samples in Fukushima prefecture for source analysis and safety assessment. Although the amounts of radioactive $\mathrm{Cs}$ and $\mathrm{Sr}$ released in this accident were very huge, the contaminated environmental samples show the small radioactivity per unit weight of the contaminated environmental samples, since the contaminated area is very wide. For the study of the recovery/analysis method of cesium and strontium, at first, the radioactive $\mathrm{Cs}$ and $\mathrm{Sr}$ were generated by the irradiation of natural uranium at KUR. After this study, the applicability of this method to the environmental samples obtained in Fukushima prefecture was verified.

\subsection{Experimental}

\subsubsection{Irradiation of $\mathrm{UO}_{2}$ for Study of Radioactive Cs and $\mathrm{Sr}$}

$10 \mathrm{mg}$ of $\mathrm{UO}_{2}$ of natural uranium was irradiated for $3 \mathrm{~h}$ at the Kyoto University Research Reactor with the neutron flux $5.5 \times 10^{12} \mathrm{n} / \mathrm{s} \mathrm{cm}^{2}$. From the calculation with ORIGEN-II code [8], the amounts of the major radionuclide of $\mathrm{Cs}$ and $\mathrm{Sr}$ were estimated as $7.4 \times 10^{-11} \mathrm{~g}\left({ }^{137} \mathrm{Cs}\right)$ and $4.5 \times 10^{-11} \mathrm{~g}\left({ }^{90} \mathrm{Sr}\right)$, respectively. After standing for $c a .2$ days, radioactive $\mathrm{Cs}$ and $\mathrm{Sr}$ were recovered and analyzed. 


\subsubsection{Recovery of $\mathrm{Cs}$ and $\mathrm{Sr}$}

\subsubsection{Isolation of TRU Elements}

Cs and Sr were recovered with UTEVA $^{\mathrm{TM}}$-resin (100-150 $\mu \mathrm{m}$, Eichrom Technologies), Sr-resin (100-150 $\mu \mathrm{m}$, Eichrom Technologies), ammonium phosphomolybdate (AMP), the cation exchange resin DOWEX ${ }^{\mathrm{TM}}$ 50WX8 (100-200 mesh), and the anion exchange resin DOWEX ${ }^{\mathrm{TM}} 1 \mathrm{X} 8$ (100-200 mesh).

The irradiated $\mathrm{UO}_{2}$ was dissolved in $8 \mathrm{M} \mathrm{HNO}_{3}$ (TAMAPURE-AA-100) and was evaporated to dryness at $403 \mathrm{~K} .8 \mathrm{M} \mathrm{HNO}_{3}$ was added and the insoluble residues removed by centrifugation. After centrifugation, $\mathrm{H}_{2} \mathrm{O}_{2}$ (TAMAPURE-AA 100) was added for the preparation of $8 \mathrm{M} \mathrm{HNO}_{3} / 0.3 \% \mathrm{H}_{2} \mathrm{O}_{2}$ sample solution to isolate TRU elements such as $\mathrm{U}$ and $\mathrm{Pu}$ by the extraction chromatography with UTEVA-resin [9].

Three milliliter of the UTEVA-resin conditioned with diluted nitric acid was filled into a column of $54 \mathrm{~mm}$ in length and $6.5 \mathrm{~mm}$ in diameter and pretreated with $10 \mathrm{~mL}$ of $8 \mathrm{M} \mathrm{HNO}_{3} / 0.3 \% \mathrm{H}_{2} \mathrm{O}_{2}$ before loading the solution. After loading the solution, the UTEVA-resin was rinsed with $8 \mathrm{M} \mathrm{HNO}_{3}$ to elute alkaline earth metal elements [10]. The effluent was evaporated to dryness and dissolved in $10 \mathrm{~mL}$ of $3 \mathrm{M} \mathrm{HNO}_{3}$ solution for the extraction chromatography with Sr-resin.

\subsubsection{Recovery of Strontium}

The solution was loaded to the Sr-resin conditioned with diluted nitric acid and filled into a column of $54 \mathrm{~mm}$ in length and $6.5 \mathrm{~mm}$ in diameter up to $3 \mathrm{~mL}$. This effluent was evaporated at $403 \mathrm{~K}$ and the residue dissolved in $0.05 \mathrm{M} \mathrm{HNO}_{3}$ for the recovery of Cs. After washing of the Sr-resin with $3 \mathrm{M} \mathrm{HNO}_{3}, \mathrm{Sr}$ was recovered with $20 \mathrm{~mL}$ of $0.05 \mathrm{M} \mathrm{HNO}_{3}$, evaporated to dryness, and dissolved in $10 \mu \mathrm{L}$ of $1 \mathrm{M}$ $\mathrm{HNO}_{3}$.

\subsubsection{Recovery of Cesium}

After adding of $0.1 \mathrm{~g}$ of AMP to the Cs solution and stirring for several hours, the supernatant was removed from the mixed solution by centrifugation. A $20 \mathrm{~mL} 3 \mathrm{M}$ ammonium hydroxide (TAMAPURE-AA 100) solution was used to dissolve the residue for subsequent anion-exchange ion chromatography.

After the final conditioning [11], a $3 \mathrm{~mL}$ portion of the anion-exchange resin was added to a column of $54 \mathrm{~mm}$ in length and $6.5 \mathrm{~mm}$ in diameter. The sample solution was added to the column, and the resulting eluate was collected and heated to dryness. The residue was dissolved in $20 \mathrm{~mL}$ of $0.1 \mathrm{M} \mathrm{HNO}_{3}$ for the final purification with the cation-exchange ion chromatography. 
The cation-exchange resin conditioned with hydrofluoric acid (TAMAPUREAA-100), etc. [12] was filled into a column of $42 \mathrm{~mm}$ in length and $5.0 \mathrm{~mm}$ in diameter up to $1.5 \mathrm{~mL}$. After loading the sample solution, the resin was washed with diluted nitric acid followed by $20 \mathrm{~mL}$ of $1.5 \mathrm{M} \mathrm{HCl}$ (TAMAPURE-AA 100) to recover Cs. The effluent was heated to dryness, and the residue was dissolved in $20 \mu \mathrm{L}$ of $1 \mathrm{M} \mathrm{HNO}_{3}$ for the analysis of the isotopic composition of Cs.

\subsubsection{Analysis of Isotopic Composition of Cesium and Strontium}

Isotopic compositions of Cs and Sr were measured with a TIMS (Triton-T1, Thermo Fisher Scientific). A $1 \mu \mathrm{L}$ aliquot of each solution was loaded onto a rhenium filament with a TaO activator [13]. The standard material of SRM987 [14] was used as a reference material of mass spectrometry of Sr. The mass spectra of radioactive $\mathrm{Cs}$ and Sr were obtained with a secondary electron multiplier detector (SEM) because of the low total amounts of radionuclide loaded onto the filament.

\subsubsection{Analysis of Environmental Samples}

The plant samples were obtained from the south area of Iitate village, the northeast area of Okuma town, the southeast area of Futaba town, and southwest area of Futaba town in Fukushima prefecture from November 2012 and May 2013 (Table 4.1). The samples were washed three times with pure water and dried at $373 \mathrm{~K}$. About $2.5 \mathrm{~g}$ of the dried samples was incinerated with a ring furnace at $873 \mathrm{~K}$ and dissolved in concentrated $\mathrm{HNO}_{3}$ at $403 \mathrm{~K}$ and evaporated to dryness. $20 \mathrm{~mL}$ of $8 \mathrm{HNO}_{3}$ was added and the insoluble residues removed by centrifugation for the preparation of recovery of Cs and Sr. Recovery of Cs and Sr from environmental samples was also carried out by the same manner described above.

The concentration of ${ }^{88} \mathrm{Sr}$ was measured with an inductively coupled quadrupole mass spectrometer (ICP-QMS, HP-4500, Yokoagawa) and radioactivity of ${ }^{90} \mathrm{Sr}$ by Cherenkov counting [15]. The total concentration of radioactive Cs was measured by $\gamma$-spectrometry. The sample solutions were prepared as $50 \mathrm{ppm}$ of ${ }^{88} \mathrm{Sr}$ in $1 \mathrm{M}$ $\mathrm{HNO}_{3}$ for the analysis of $\mathrm{Sr}$ and $5000 \mathrm{~Bq} / \mathrm{mL}$ for ${ }^{137} \mathrm{Cs}$ in $1 \mathrm{M} \mathrm{HNO}_{3}$ for the analysis of Cs. The mass spectra of radioactive Cs and Sr were obtained with a SEM, while those of stable Cs and Sr were obtained with Faraday cup detector, since the amounts of stable nuclide were much larger than those of radionuclide. 
Table 4.1 List of samples and results of ${ }^{87} \mathrm{Sr} /{ }^{86} \mathrm{Sr}$ isotopic ratio measurement

\begin{tabular}{|c|c|c|c|c|}
\hline Sampling area & Sample ID & Type & $\delta_{87 / 86^{a}}$ & Remarks \\
\hline \multirow[t]{8}{*}{$\begin{array}{l}\text { Iitate village } \\
(37.61 \mathrm{~N}, \\
140.80 \mathrm{E})\end{array}$} & ITT01 & \multirow[t]{7}{*}{$\begin{array}{l}\text { Grass } \\
\text { (Artemisia } \\
\text { indica) }\end{array}$} & $-3.28(01)$ & \multirow[t]{8}{*}{$\begin{array}{l}\text { ITT01 to } 07 \\
\text { were prepared } \\
\text { by division of } \\
\text { one sample }\end{array}$} \\
\hline & ITT02 & & $-3.04(04)$ & \\
\hline & ITT03 & & $-3.20(09)$ & \\
\hline & ITT04 & & $-3.05(07)$ & \\
\hline & ITT05 & & $-3.11(07)$ & \\
\hline & ITT06 & & $-3.13(08)$ & \\
\hline & ITT07 $^{\mathrm{b}}$ & & $-3.14(04)$ & \\
\hline & & ITT-av & $-3.14(06)$ & \\
\hline \multirow{3}{*}{$\begin{array}{l}\text { Okuma town } \\
(37.41 \mathrm{~N} \text {, } \\
141.03 \mathrm{E})\end{array}$} & OKM01 ${ }^{\mathrm{b}}$ & Moss & $-1.42(12)$ & \\
\hline & $\mathrm{OKM} 02^{\mathrm{c}}$ & Moss & $-1.83(05)$ & \\
\hline & OKM03 & $\begin{array}{l}\text { Bark } \\
\text { (Metasequoia } \\
\text { glyp- } \\
\text { tostroboides) }\end{array}$ & $-4.42(08)$ & \\
\hline \multirow[t]{6}{*}{$\begin{array}{l}\text { Futaba town-1 } \\
(37.45 \mathrm{~N}, \\
141.62 \mathrm{E})\end{array}$} & ${\text { FTB } 01^{\mathrm{b}}}^{\mathrm{b}}$ & $\begin{array}{l}\text { Bark } \\
\text { (Cryptomeria } \\
\text { japonica) }\end{array}$ & $-2.51(08)$ & \\
\hline & FTB02 & $\begin{array}{l}\text { Leaves of tree } \\
\text { (Camellia } \\
\text { japonica) }\end{array}$ & $-3.75(09)$ & \\
\hline & FTB03 & Leaves of tree & $-3.87(15)$ & \multirow[t]{2}{*}{$\begin{array}{l}\text { Same tree } \\
\text { (Cryptomeria } \\
\text { japonica), 03: } \\
\text { attached leaves; } \\
\text { 04: fallen leaves }\end{array}$} \\
\hline & FTB04 & Leaves of tree & $-4.14(09)$ & \\
\hline & FTB05 & \multirow[t]{2}{*}{$\begin{array}{l}\text { Grass } \\
\text { (Artemisia } \\
\text { indica) }\end{array}$} & $-3.29(09)$ & \\
\hline & FTB06 & & $-4.23(08)$ & \\
\hline \multirow[t]{2}{*}{$\begin{array}{l}\text { Futaba town-2 } \\
(37.45 \mathrm{~N}, \\
140.94 \mathrm{E})\end{array}$} & FTB35R $^{b}$ & \multirow[t]{2}{*}{$\begin{array}{l}\text { Grass(Artemisia } \\
\text { indica) }\end{array}$} & $-2.96(08)$ & \multirow[t]{2}{*}{$\begin{array}{l}\text { Same grass, } \\
\text { 35R: roots; } \\
35 \text { L: leaves }\end{array}$} \\
\hline & FTB35L & & $-4.30(08)$ & \\
\hline Austria & IAEA-156 & Grass (Clover) & $-2.27(03)$ & \\
\hline
\end{tabular}

${ }^{a}$ Parentheses means experimental error in \pm 2 s.d

${ }^{b}$ Isotopic ratio of radioactive Cs has been reported in our previous study [11]

${ }^{c}$ Isotopic ratio of radioactive Cs was analyzed in this study 


\subsection{Results and Discussion}

\subsubsection{Isotopic Analysis of Radioactive Cs and $\mathrm{Sr}$ from Irradiated $\mathrm{UO}_{2}$}

Figure 4.1a shows the mass spectra of $\mathrm{Cs}$ recovered from the irradiated $\mathrm{UO}_{2}$. In this measurement, ${ }^{135} \mathrm{Cs},{ }^{136} \mathrm{Cs}$, and ${ }^{137} \mathrm{Cs}$ were detected: ${ }^{134} \mathrm{Cs}$ was not detected, because of the difference in the generation scheme. The observed isotopic ratios of ${ }^{135} \mathrm{Cs} /{ }^{137} \mathrm{Cs}$ and ${ }^{136} \mathrm{Cs} /{ }^{137} \mathrm{Cs}$ were obtained as $0.9103 \pm 0.0008$ and $0.00022 \pm 0.00001$. From our calculation with ORIGEN-II code [8], the loading amounts of ${ }^{135} \mathrm{Cs},{ }^{136} \mathrm{Cs}$, and ${ }^{137} \mathrm{Cs}$ in this time were about $3.5,0.03$, and $3.7 \mathrm{pg}$ respectively. This means that the femtogram level of Cs is detectable by TIMS.

Figure 4.2 shows the mass spectra of $\mathrm{Sr}$ both of stable (a) and radioactive (b) isotopes. At the measurement of 2.6 days later, ${ }^{89} \mathrm{Sr},{ }^{90} \mathrm{Sr}$, and ${ }^{91} \mathrm{Sr}$ were detected. From our calculation with ORIGEN-II code [8], the loading amounts of ${ }^{89} \mathrm{Sr},{ }^{90} \mathrm{Sr}$, and ${ }^{91} \mathrm{Sr}$ in this time were about 3,4 , and $0.04 \mathrm{pg}$ respectively. This means that the femtogram level of $\mathrm{Sr}$ is also detectable by TIMS.

The measured isotopic ratios were 0.80 for ${ }^{89} \mathrm{Sr} /{ }^{90} \mathrm{Sr}$ and 0.01 for ${ }^{91} \mathrm{Sr} /{ }^{90} \mathrm{Sr}$ showing the agreement with the calculated value $\left(0.79\right.$ for ${ }^{89} \mathrm{Sr} /{ }^{90} \mathrm{Sr}$ and 0.01 for ${ }^{91} \mathrm{Sr} /{ }^{90} \mathrm{Sr}$ ). Because the half-life of ${ }^{91} \mathrm{Sr}$ is $9.5 \mathrm{~h}$, the mass spectrum of ${ }^{91} \mathrm{Sr}$ disappeared at the measurement of 31 days later. The measured isotopic ratio of ${ }^{89} \mathrm{Sr} /{ }^{90} \mathrm{Sr}$ is 0.53 showing the agreement with the calculated value of 0.54 . At the measurement of 574 days later, only the mass spectrum of ${ }^{90} \mathrm{Sr}$ was observed because the half-life of ${ }^{89} \mathrm{Sr}$ is 50.5 days. This means that ${ }^{89} \mathrm{Sr} /{ }^{90} \mathrm{Sr}$ could not be analyzed by using a typical mass spectrometer after Sep. 2012, if we obtain the sample containing femtogram level of ${ }^{90} \mathrm{Sr}$. The isotopic ratio of ${ }^{90} \mathrm{Sr} /{ }^{\text {stable }} \mathrm{Sr}$ would be therefore needed for our purpose.

Fig. 4.1 Mass spectra of Cs. (a) Recovered from $\mathrm{UO}_{2}$ irradiated in KUR. (b) Recovered from environmental sample from Fukushima prefecture (Reproduced from Ref [11])
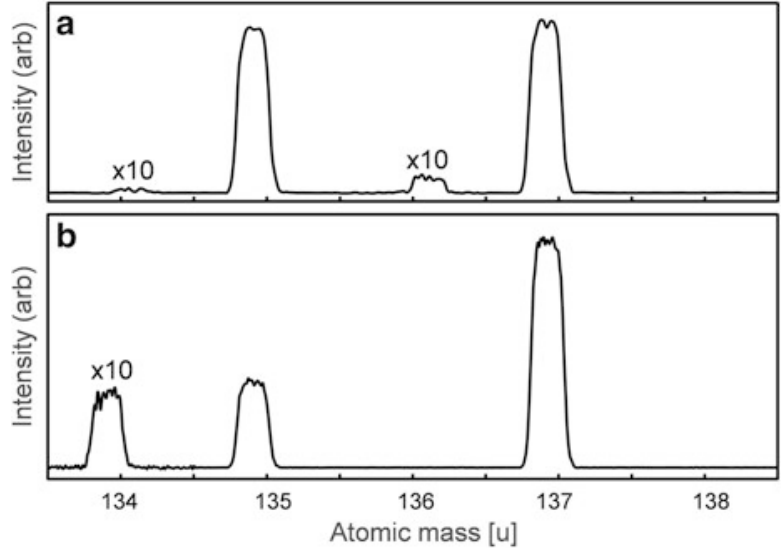


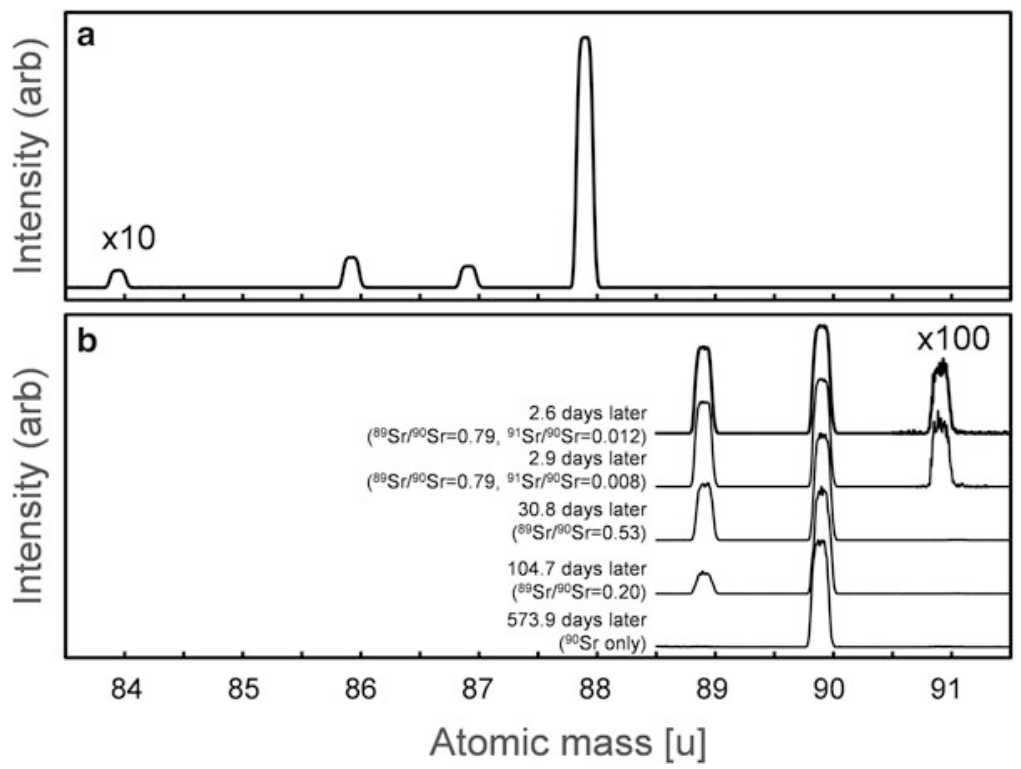

Fig. 4.2 Mass spectra of Sr. Stable isotopes (a) were obtained by measurement of Sr of SRM987 with a Faraday cup detector, and radioactive isotopes (b) were obtained by measurement of $\mathrm{Sr}$ recovered from $\mathrm{UO}_{2}$ irradiated in KUR with a secondary electron multiplier detector

\subsubsection{Analysis of Isotopic Compositions of Cs and $\mathrm{Sr}$ from Environmental Samples}

\subsubsection{Analysis of Cs}

Figure $4.1 \mathrm{~b}$ shows three peaks, representing ${ }^{134} \mathrm{Cs},{ }^{135} \mathrm{Cs}$, and ${ }^{137} \mathrm{Cs}$, were observed on the typical mass spectra of Cs recovered from environmental samples obtained in Fukushima prefecture [11], while the peak representing ${ }^{136} \mathrm{Cs}$ was not observed because of the half-life $\left(\mathrm{T}_{1 / 2}=13.2 \mathrm{~d}\right)$. From the calculation with ORIGEN-II code [1], the isotopic ratio of ${ }^{136} \mathrm{Cs} /{ }^{137} \mathrm{Cs}$ in the fuel was estimated as $\mathrm{ca} .0 .00032$. This value shows the same order compared with that of the irradiated $\mathrm{UO}_{2}$, suggesting that we could obtain the three isotopic ratios of ${ }^{134} \mathrm{Cs} /{ }^{137} \mathrm{Cs},{ }^{135} \mathrm{Cs} /{ }^{137} \mathrm{Cs}$, and ${ }^{136} \mathrm{Cs} /{ }^{137} \mathrm{Cs}$ until July 2011. Since there are three reactors in FDNPP, three isotopic ratios would bring the important information for the source analysis of radioactive $\mathrm{Cs}$ in the contaminated area in Fukushima prefecture.

Although we could not obtain the isotopic ratio of ${ }^{136} \mathrm{Cs} /{ }^{137} \mathrm{Cs}$ after July 2011, we can obtain the two-dimensional map with the isotopic ratios of ${ }^{134} \mathrm{Cs} /{ }^{137} \mathrm{Cs}$ and ${ }^{135} \mathrm{Cs} /{ }^{137} \mathrm{Cs}$ as shown in Fig. 4.3. All of the isotopic ratios of ${ }^{135} \mathrm{Cs} /{ }^{137} \mathrm{Cs}$ showed less than 0.4 . This value was also much smaller than reported isotopic ratios of global fallout ( $\sim 0.5$ for Chernobyl accident and $\sim 2.7$ for nuclear weapon testing, corrected 


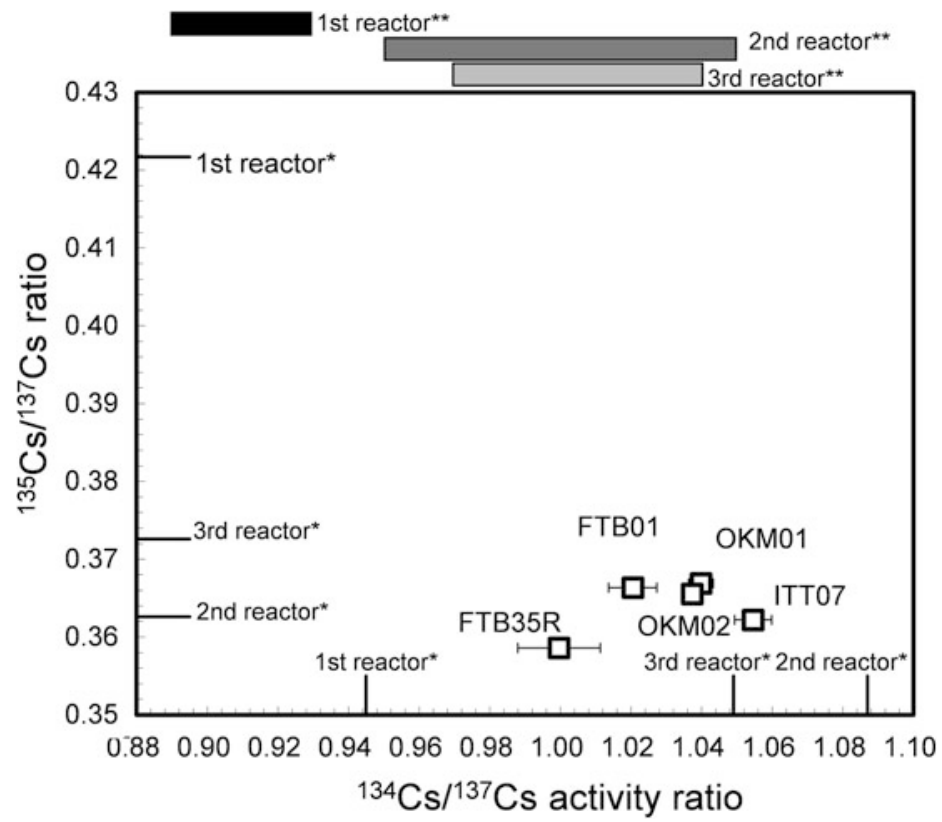

Fig. 4.3 ${ }^{135} \mathrm{Cs} /{ }^{137} \mathrm{Cs}$ (atomic ratio) vs ${ }^{134} \mathrm{Cs} /{ }^{137} \mathrm{Cs}$ (activity ratio). Error here means $\pm 2 \mathrm{SE}$. Data of OKM01, FTB01, FTB35R and ITT07 were reproduced from Ref [11]. Both of isotopic ratio was corrected to March 11, 2011. Single asterisk (*) represents calculation results from estimation of radioactive nuclides with ORIGEN-II code [1]. Double asterisk $(* *)$ represents values reported for ${ }^{134} \mathrm{Cs} /{ }^{137} \mathrm{Cs}$ activity ratio in polluted water [22]

to March 11, 2011 [11]) and the long half-life of ${ }^{135} \mathrm{Cs}\left(\mathrm{T}_{1 / 2}=2.3 \times 10^{6} \mathrm{y}\right)$, meaning that only the isotopic ratio of ${ }^{135} \mathrm{Cs} /{ }^{137} \mathrm{Cs}$ would also provide the information for the origin of radioactive $\mathrm{Cs}$ among Chernobyl accident, nuclear weapon testing, and FDNPP accident for the long term.

\subsubsection{Analysis of $\mathrm{Sr}$}

The FP of $\mathrm{Sr}$ in each reactor has mainly five isotopes [1]: two stable isotopes of ${ }^{86} \mathrm{Sr}$ and ${ }^{88} \mathrm{Sr}$ and three radioactive isotopes of ${ }^{89} \mathrm{Sr},{ }^{90} \mathrm{Sr}$, and ${ }^{91} \mathrm{Sr}$. The relationship between the isotopic ratio of radioactive $\mathrm{Cs}$ and that of $\mathrm{Sr}$ estimated by ORIGEN Code calculation [1] is plotted in Fig. 4.4. In addition to the radioactive isotopes, the stable isotopes of $\mathrm{Sr}$ generated in each reactor show the characteristic profile. This suggests that the stable isotopes of Sr could be also used for the analysis of the FP of Sr.

Among the isotopic ratios of stable isotopes, the isotopic ratio of ${ }^{87} \mathrm{Sr} /{ }^{86} \mathrm{Sr}$ is important in the field of the geological chronology [16], because ${ }^{87} \mathrm{Sr}$ is generated by the $\beta$-decay of ${ }^{87} \mathrm{Rb}$ having the half-life of $4.9 \times 10^{10} \mathrm{y}$. Thus, the isotopic ratio of stable isotopes, in this study, will be focused on the isotopic ratio of ${ }^{87} \mathrm{Sr} /{ }^{86} \mathrm{Sr}$. 


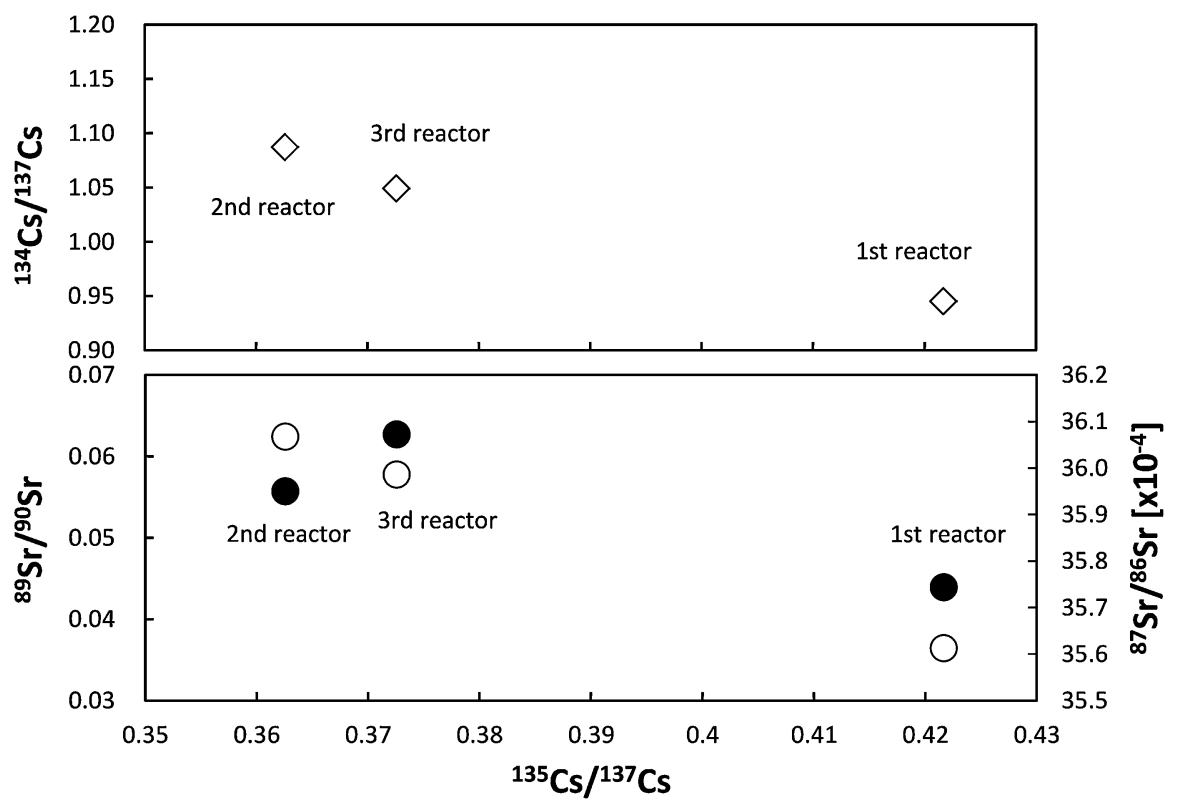

Fig. 4.4 Estimated relationship between isotopic ratios of ${ }^{134} \mathrm{Cs} /{ }^{137} \mathrm{Cs},{ }^{89} \mathrm{Sr} /{ }^{90} \mathrm{Sr}$ and ${ }^{87} \mathrm{Sr} /{ }^{86} \mathrm{Sr}$ and that of ${ }^{135} \mathrm{Cs} /{ }^{137} \mathrm{Cs}$. Isotopic ratios were estimated by calculation results with ORIGEN Code [1]. Open circle means isotopic ratio of ${ }^{89} \mathrm{Sr} /{ }^{90} \mathrm{Sr}$. Closed circle represents isotopic ratio of ${ }^{87} \mathrm{Sr} /{ }^{86} \mathrm{Sr}$

The certified value for SRM987 of the isotopic ratio of ${ }^{87} \mathrm{Sr} /{ }^{86} \mathrm{Sr}$ showing the $95 \%$ confidence intervals is $0.71036 \pm 0.00026$ [14]. The averaged measurement value was obtained as $0.71025 \pm 0.00002(n=26)$ showing the agreement with the certified value.

In this study, the variations in the isotopic ratio of ${ }^{87} \mathrm{Sr} /{ }^{86} \mathrm{Sr}$ were normalized with that of SRM987; this would be expressed as delta-value $\left(\delta_{87 / 86}\right)$ in per mill notation as the following equation:

$$
\delta_{87 / 86}=\left(\frac{\left({ }^{87} \mathrm{Sr} /{ }^{86} \mathrm{Sr}\right) \text { sample }}{\left({ }^{87} \mathrm{Sr} /{ }^{86} \mathrm{Sr}\right) \mathrm{SRM} 987}\right) \times 1000 .
$$

The samples of ITT01 to ITT07 were prepared by the division of one sample. The $\delta_{87 / 86}-$ values of samples ITT01 to ITT07 in Table 4.1 agreed within the error showing the reproducibility of the isotopic ratio measurement including chemical treatment. From the $\delta_{87 / 86}-$ values of samples ITT01 to ITT07, the averaged $\delta_{87 / 86^{-}}$ value of them was obtained to be $\delta_{87 / 86}=-3.14 \pm 0.06 \%$.

The results of the isotopic ratio measurements for all samples are summarized in Table 4.1 and shownin Fig. 4.5a. The result of the measurement for the reference material of IAEA-156: Radionuclides in clover [17] is also included. This reference material contains $\mathrm{ca}$. $0.0075 \mathrm{~Bq} / \mathrm{g}$ in June 2015 . The $\delta_{87 / 86}$-values of the samples of 


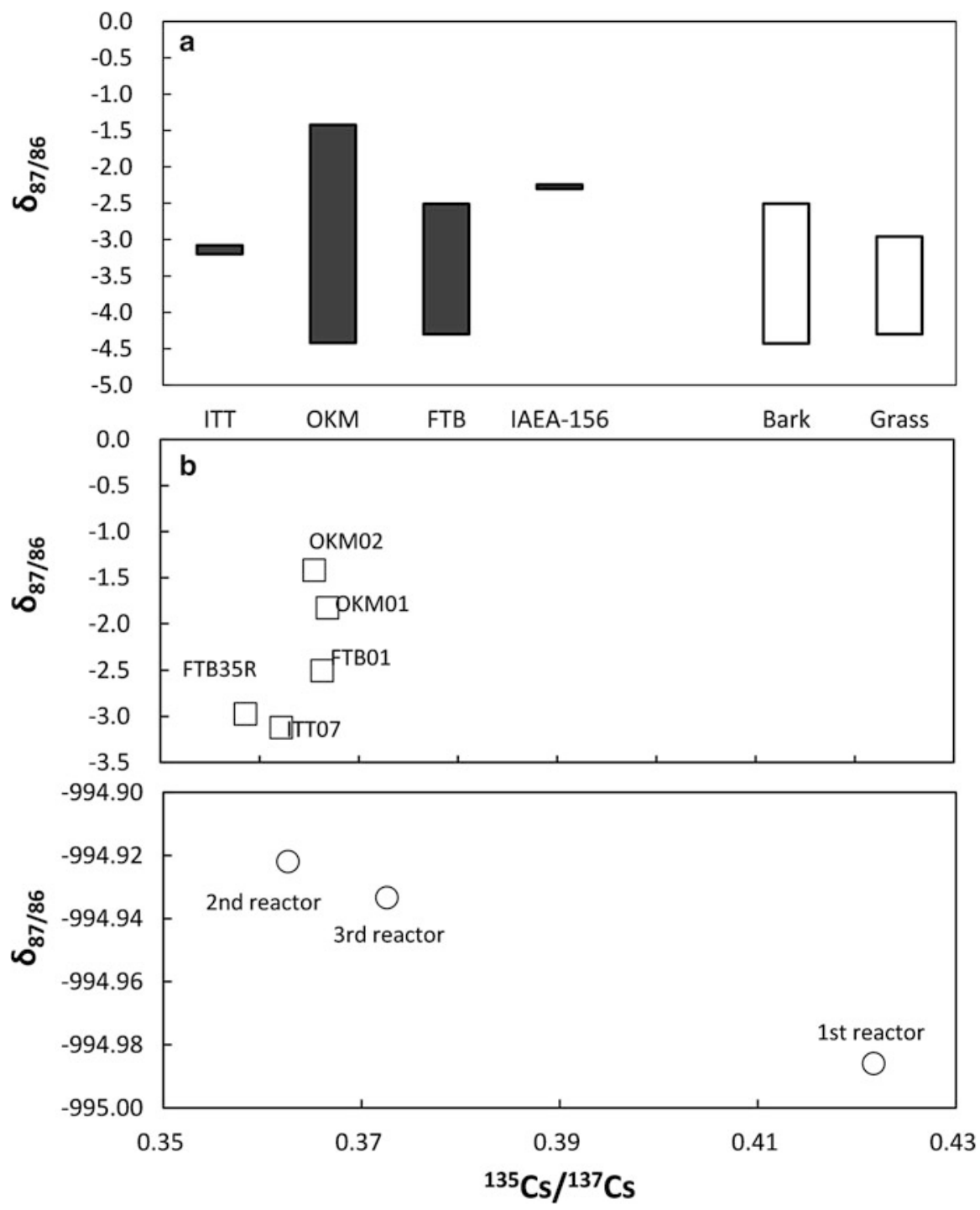

Fig. 4.5 Results of ${ }^{87} \mathrm{Sr} /{ }^{86} \mathrm{Sr}$ isotopic ratio measurement for plant samples (a), and isotopic ratio of ${ }^{87} \mathrm{Sr} /{ }^{86} \mathrm{Sr}$ as a function of ${ }^{135} \mathrm{Cs} /{ }^{137} \mathrm{Cs}(\mathbf{b})$. Bark is results of comparison between OKM03 and FTB01. Grass shows results of comparison between FTB35R and FTB35L. Isotopic ratio of ${ }^{135} \mathrm{Cs} /{ }^{137} \mathrm{Cs}$ of OKM01, FTB01, FTB35R and ITT07 were reproduced from Ref [11], and used after time correlation on March 11, 2011. Open square and open circle mean analytical results in this study and results of estimation by calculation results with ORIGEN Code [1] 
Okuma range from -1.4 to -4.4 , while those of Futaba range from -2.5 to -4.2 . It is found that these values have significant difference, by comparison with the $\delta_{87 / 86^{-v a l u e ~ o f ~ I i t a t e ~ s a m p l e s . ~}}$

Though the samples OKM03 and FTB01 are bark samples from the plants of the same family, these showed different magnitudes (Fig. 4.5a and Table 4.1). The isotopic ratio of ${ }^{87} \mathrm{Sr} /{ }^{86} \mathrm{Sr}$ has received attention as the indicator of the production region of plants and reported the $\delta_{87 / 86}-$ values ranged from -25.0 to 5.5 [18]. As the reason of the difference in the $\delta_{87 / 86}-$ values among samples OKM03 and FTB01, two origins could be considered: the first is the difference in the $\delta_{87 / 86}$-values of soils of sampling point (as the supply source of Sr) and the second is the difference in the degree of the isotope fractionation during the translocation process (considered as the reason of the difference in the isotopic ratio between the parts of the identical organism). Because of the comparison of the $\delta_{87 / 86^{-}}$values of the same parts in this case, the difference in the $\delta_{87 / 86}$-value among samples OKM03 and FTB01 might be caused by the soils in sampling area.

If the difference of $\delta_{87 / 86^{-}}$-values between samples OKM03 and FTB01 originated from a difference of contamination level by the $\mathrm{FP}$ of $\mathrm{Sr}$, the isotopic ratio may show a correlation as

$$
\begin{aligned}
\left(\left[{ }^{87} \mathrm{Sr}\right]_{\text {OKM } 03} /\left[{ }^{86} \mathrm{Sr}\right]_{\text {OKM } 03}\right)= & \left(\left[{ }^{87} \mathrm{Sr}\right]_{\mathrm{nat}} /\left[{ }^{86} \mathrm{Sr}\right]_{\mathrm{nat}}\right) \times(1-X) \\
& +\left(\left[{ }^{87} \mathrm{Sr}\right]_{\mathrm{FP}} /\left[{ }^{86} \mathrm{Sr}\right]_{\mathrm{FP}}\right) \times X, \\
\left(\left[{ }^{87} \mathrm{Sr}\right]_{\mathrm{FTB} 01} /\left[{ }^{86} \mathrm{Sr}\right]_{\mathrm{FTB} 01}\right)= & \left(\left[{ }^{87} \mathrm{Sr}\right]_{\mathrm{nat}} /\left[{ }^{86} \mathrm{Sr}\right]_{\mathrm{nat}}\right) \times(1-Y) \\
& +\left(\left[{ }^{87} \mathrm{Sr}\right]_{\mathrm{FP}} /\left[{ }^{86} \mathrm{Sr}\right]_{\mathrm{FP}}\right) \times Y .
\end{aligned}
$$

According to the relation and the concentrations of Sr; $72 \mathrm{ppm}$ for OKM03 and $24 \mathrm{ppm}$ for FTB03, the amount of the FP of ${ }^{86} \mathrm{Sr}$ contained in the sample OKM03 would be higher than that of FTB01, about $10.3 \mathrm{ng}$. This is equivalent to $c a .10 .5 \mu \mathrm{g}$ of ${ }^{90} \mathrm{Sr}\left(c a .5 .3 \times 10^{7} \mathrm{~Bq}\right)$ according to the averaged isotopic ratio of ${ }^{90} \mathrm{Sr} /{ }^{86} \mathrm{Sr}$ of the FP of Sr [1]. ${ }^{90} \mathrm{Sr}$ was not found in the plant samples by TIMS and Cherenkov counting having the detection limit of several ten $\mathrm{mBq} / \mathrm{g}$ [15], however, suggesting that our samples contain ${ }^{90} \mathrm{Sr}<<10 \mathrm{fg}$ and was less than $1 \mathrm{~Bq} / \mathrm{g}$.

Sample FTB35R is roots, while FTB35L is leaves, of the same plant. The $\delta_{87 / 86^{-}}$ values (Fig. 4.5a and Table 4.1) showed a significant difference. Sample FTB35R shows higher $\delta_{87 / 86}$-value compared with sample FTB35L. The isotopic fractionations were observed in some biological processes. For example, the isotopic analysis of $\mathrm{Sr}$ [19], Fe [20], and $\mathrm{Zn}$ [21] proves that roots are isotopically heavy compared with the aerial parts; the maximum $\delta_{87 / 86^{-}}$-value was $c a .-5.0$ for $\mathrm{Sr}$, the maximum $\delta_{56 / 54}$-value was $c a$. -1.4 for $\mathrm{Fe}$, and the maximum $\delta_{66 / 64}$-value was $c a .-0.26$ for $\mathrm{Zn}$, respectively. Since the Cherenkov counting showed the amounts of ${ }^{90} \mathrm{Sr}$ in these samples were under the detection limit, the difference in the $\delta_{87 / 86}$-value between samples FTB35R and FTB35L might be caused by the isotopic fractionations in the biological processes along with the contamination of sample FTB35R by the soil. 
The isotopic ratios of radioactive Cs in samples FTB01, OKM01, FTB35R, and ITT07 measured by TIMS have been reported in our previous study [11], and that in OKM02 was measured in this study. The relationships between the isotopic ratio of ${ }^{87} \mathrm{Sr} /{ }^{86} \mathrm{Sr}$ as $\delta_{87 / 86}$-value of these samples and that of ${ }^{135} \mathrm{Cs} /{ }^{137} \mathrm{Cs}$ are plotted in Fig. 4.5b. The isotopic ratios of ${ }^{135} \mathrm{Cs} /{ }^{137} \mathrm{Cs}$ show the significant difference from the reported values of the global fallout ( $c a .0 .5$ for Chernobyl accident and $c a .2 .7$ for nuclear weapon testing corrected on March 11, 2011 [11]), while these values agreed with the estimated values with the results of ORIGEN Code calculation [1]. This means that all of the samples are contaminated by radioactive Cs released from FDNPP. The $\delta_{87 / 86}$-values of these samples, on the other hand, are far from that of the FP calculated by ORIGEN Code [1]. This suggests that the amount of deposit of 90Sr is very little compared with that of Cs and agrees with our previous report [15].

Although ${ }^{90} \mathrm{Sr}$ was not found in the plant samples suggesting that our samples contain ${ }^{90} \mathrm{Sr}<<10 \mathrm{fg}$, typical mass spectrometers have the external analytical precision of ppm level. Assumed that this precision could be applied for the isotopic ratio of ${ }^{90} \mathrm{Sr} /{ }^{\text {stables }} \mathrm{Sr}$, the isotopic ratio of ${ }^{90} \mathrm{Sr} /{ }^{\text {stable }} \mathrm{Sr}$ must be higher than $10^{-6}$. For the natural sample, since the $\mathrm{Sr}$ concentration ranges from ppb level to several hundred ppm level (Fig. 4.6), the detectable lower limit of the isotopic ratio of ${ }^{90} \mathrm{Sr} /{ }^{\text {stable }} \mathrm{Sr}$ can be evaluated.

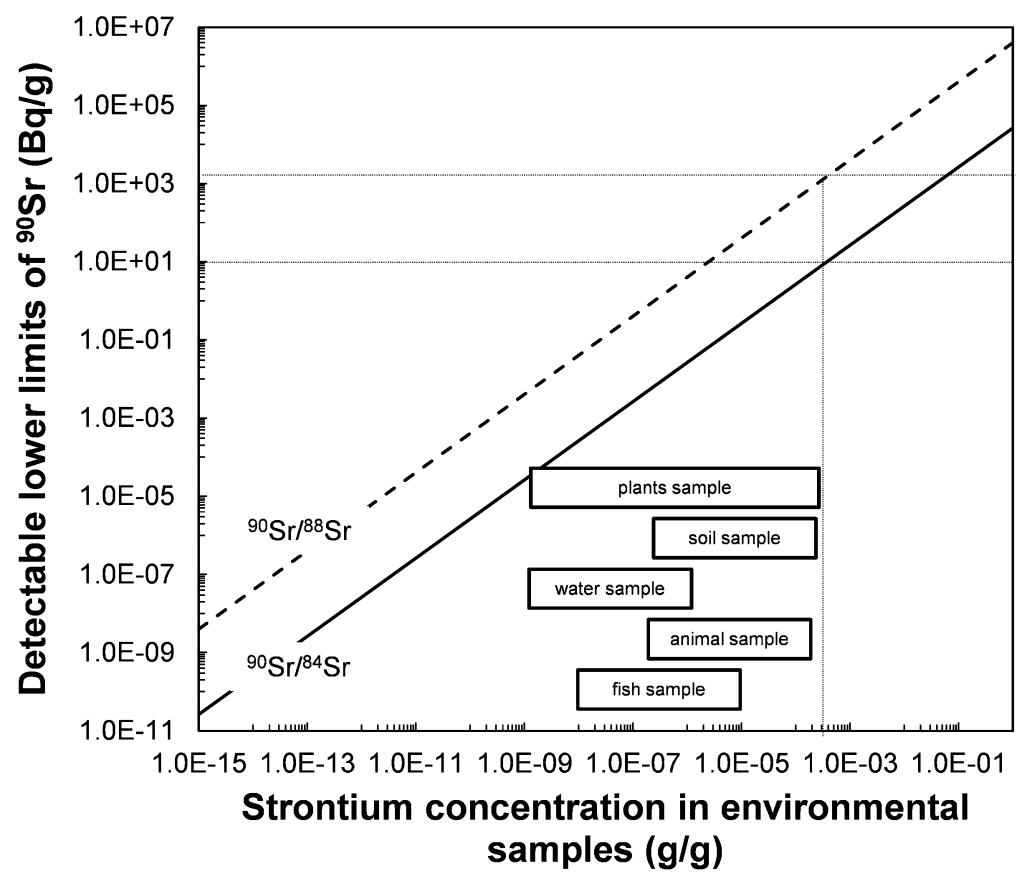

Fig. 4.6 Detectable lower limits of ${ }^{90} \mathrm{Sr}$ in environmental samples with TIMS. Solid line indicates a limit for ${ }^{90} \mathrm{Sr} /{ }^{84} \mathrm{Sr}$, and broken line a limit for ${ }^{90} \mathrm{Sr} /{ }^{88} \mathrm{Sr}$ 
If ${ }^{88} \mathrm{Sr}$ having the natural abundance $c a .82 \%$ was used as reference isotope, the concentration of ${ }^{90} \mathrm{Sr}$ should be higher than $1 \mathrm{~Bq} / \mathrm{g}$ in almost any type of sample. When the isotopic ratio of ${ }^{90} \mathrm{Sr} /{ }^{84} \mathrm{Sr}$ is used, because the abundance of ${ }^{84} \mathrm{Sr}$ ( $c a$. $0.56 \%$ ) is lower than that of ${ }^{88} \mathrm{Sr}$, the applicable range will become much wider than the case of ${ }^{88} \mathrm{Sr}$ (Fig. 4.5). The improvement in the sensitivity of ${ }^{90} \mathrm{Sr}$ detection and the obtaining of samples including small amounts of natural $\mathrm{Sr}$ will also bring wide applicable range.

\subsection{Conclusions}

Cs and Sr recovered from samples were analyzed by TIMS to study the applicability of TIMS for safety assessment and source analysis.

For the study of the recovery/analysis method of $\mathrm{Cs}$ and $\mathrm{Sr}, \mathrm{Cs}$ and $\mathrm{Sr}$ were recovered from the natural uranium irradiated at KUR. From the measurement of radionuclide recovered from irradiated $\mathrm{UO}_{2}$, it was concluded that several tens of femtogram level of radionuclide is detectable.

$\mathrm{Cs}$ and $\mathrm{Sr}$ were recovered from the environmental samples obtained from Fukushima prefecture and were analyzed by a method based on the results of irradiated $\mathrm{UO}_{2}$. In the case of the analysis of $\mathrm{Cs}$, it was confirmed that the analysis of the radioactive Cs by TIMS would provide important information for the source analysis. The isotopic ratio of ${ }^{135} \mathrm{Cs} /{ }^{137} \mathrm{Cs}$ was useful for the precise evaluation of the radioactive Cs from FDNPP apart from that of global fallout after the radioactivity of ${ }^{134} \mathrm{Cs}$ became below the detection limit of $\gamma$-ray measurement.

In the case of the analysis of $\mathrm{Sr}$, on the other hand, the presence of ${ }^{90} \mathrm{Sr}$ was not detected in any samples, while the changes in the isotopic ratios of ${ }^{87} \mathrm{Sr} /{ }^{86} \mathrm{Sr}$ were observed. From the discussion for the amount of the FP of $\mathrm{Sr}$, it was conjectured that the changes in the isotopic ratios of ${ }^{87} \mathrm{Sr} /{ }^{86} \mathrm{Sr}$ might be brought by some isotopic fractionation in the biological processes. The evaluation of the detectable lower limit of the isotopic ratio of ${ }^{90} \mathrm{Sr} /{ }^{\text {stable }} \mathrm{Sr}$ suggests that the isotopic ratio of ${ }^{90} \mathrm{Sr} /{ }^{84} \mathrm{Sr}$ is the most suitable index to judge a source of radioactive $\mathrm{Sr}$ released during the accident of FDNPP by TIMS.

Open Access This chapter is distributed under the terms of the Creative Commons Attribution Noncommercial License, which permits any noncommercial use, distribution, and reproduction in any medium, provided the original author(s) and source are credited.

\section{References}

1. Nishihara K, Iwamoto H, Suyama K (2012) JAEA-data/code 2012-018 [in Japanese]

2. Karam LR, Pibida L, McMahon CA (2002) Appl Rad Isot 56:369-374

3. Pibida L, MacMahon CA, Busharw BA (2004) Appl Rad Isot 60:567-570 
4. Taylor VF, Evans RD, Cornett RJ (2008) J Environ Radact 99:109-118

5. Delmore JE, Snyder DC, Tranter T, Mann NR (2011) J Environ Radact 102:1008-1011

6. Snyder DC, Delmore JE, Tranter T, Mann NR, Abbott ML, Olson JE (2012) J Environ Radact 110:46-52

7. Berglund M, Wieser ME (2011) Pure Appl Chem 83:397-410

8. Ludwig SB, Renier JP (1989) Standard- and extended-Burnup PWR and BWR reactor models for the ORIGEN2 Computer Code. Oak Ridge National Laboratory, ORNL/TM-11018

9. Shibahara Y, Kubota T, Fujii T, Fukutani S, Ohta T, Takamiya K, Okumura R, Mizuno S, Yamana H (2015) J Radioanal Nucl Chem 303:1421-1424

10. Lee MH, Park JH, Oh SY, Ahn HJ, Lee CH, Song K, Lee MS (2011) Talanta 86:99-102

11. Shibahara Y, Kubota T, Fujii T, Fukutani S, Ohta T, Takamiya K, Okumura R, Mizuno S, Yamana H (2014) J Nucl Sci Technol 51:575-579

12. Yoshikawa M, Nakamura E (1993) J Min Petr Econ Geol 88:548-561

13. Birck JL (1986) Chem Geol 56:73-83

14. https://www-s.nist.gov/srmors/view_detail.cfm?srm=987. Accessed 20 Aug 2014

15. Kubota T, Shibahara Y, Fujii T, Fukutani S, Ohta T, Takamiya K, Okumura R, Mizuno S, Yamana H (2015) J Radioanal Nucl Chem 303:39-46

16. Faure G, Powell JL (1972) Strontium isotope geology. Springer, New York

17. Strachnov V, Valkovic V, Dekner R (1991) Report on the intercomparison run IAEA-156: radionuclides in clover. International Atomic Energy Agency, Austria, IAEA/AL/035

18. Almeida CM, Vasconcelos MTSD (2001) J Anal At Spectrom 16:607-611

19. de Souza GF, Reynolds BC, Kiczka M, Bourdon B (2010) Geochim Gosmochim Acta 74:2596-2614

20. Moynier F, Fujii T, Wang K, Foriel J (2013) Compt Rend Geosci 345:230-240

21. Weiss DJ, Mason TFD, Zhao FJ, Kirk GJD, Coles BJ, Horstwood MSA (2005) New Phytol 165:703-710

22. Komori M, Shozugawa K, Nogawa N, Matsuo M (2013) Bunseki Kagaku 62:475-483 [in Japanese] 